\title{
How to Solve the Puzzle of Dion and Theon Without Losing Your Head
}

\author{
Chad Carmichael \\ Indiana University-Purdue University Indianapolis \\ crcarmic@iupui.edu
}

\begin{abstract}
The ancient puzzle of Dion and Theon has given rise to a surprising array of apparently implausible views. For example, in order to solve the puzzle, several philosophers have been led to deny the existence of their own feet, others have denied that objects can gain and lose parts, and large numbers of philosophers have embraced the thesis that distinct objects can occupy the same space, having all their material parts in common. In this paper, I argue for an alternative approach: I claim that human beings have ordinary partshands, heads, feet, and so on—but no extraordinary parts, such as 'foot-complements', the existence of which is essential to the puzzle. I rebut three objections to this approach: the objection that it is unacceptably metaphysically arbitrary, an objection that the view is incompatible with versions of the puzzle involving decapitation, and an objection concerning masses of matter. If we can believe that there are such things as hands and feet without ending up involved in paradox, and without accepting large numbers of co-located material objects that share all their material parts, then that is what we should do. My view is the only known alternative which allows this.
\end{abstract}

\section{Introduction}

Suppose that Dion is a regular man whose left foot is annihilated at time t. Prior to t, Dion is exactly located in a region that is shaped like a fully intact man. After losing his foot, Dion is exactly located in a region (call it $\mathrm{R}$ ) that is shaped like a man who is missing his left foot. If there was an object inhabiting R prior to t—what we might call Dion's 'leftfoot complement', which Chrysippus named Theon—-then one might wonder exactly what

This is the author's manuscript of the article published in final edited form as:

Carmichael, C. (2020). How to Solve the Puzzle of Dion and Theon Without Losing Your Head. Mind, 129(513), $205-224$. https://doi.org/10.1093/mind/fzy021 
the relationship is between Dion and this object after $\mathrm{t}^{1}{ }^{1}$ Several views of the situation have been defended in the literature:

Dion and Theon both exist before t, but Dion no longer exists after $t$, while Theon remains.

Dion and Theon both exist before $t$, but Theon no longer exists after $t$, while Dion remains.

Neither Dion nor Theon ever existed.

Dion existed throughout, but Theon never existed, nor did Dion's feet, his head, etc.

Dion and Theon end up in the same place, having all the same material parts after t.

Most of these views are obviously implausible. The first view is implausible because it entails that Dion cannot survive the loss of a foot. The second view is implausible because it entails that an object can be destroyed merely by being detached from an adjacent object that is not a part of it. The third view is implausible because it is inconsistent with the obvious fact that human beings exist. The fourth view is implausible because it is inconsistent with the obvious fact that people often have feet.

The fifth view is perhaps less obviously implausible. It is probably the most popular view of the matter in the literature. While there is much to say here, I will content myself with just one point. Suppose that you will grow an additional arm in a moment. Once you do so, on the fifth view, you will have a 'new-arm complement'. This object will not have come into existence upon the growth of your new arm; as noted above, it is implausible that we can destroy an object just by detaching it from an adjacent object that is not a part of it, and, similarly, it is implausible that we can bring an object into existence merely by adjoining an object to it that is never one of its parts. Thus, on the fifth view, given our assumption that you will grow a new arm, you would currently be co-located with an object which is distinct from you, but shares all your matter. This is already hard to swallow. But it gets worse: if we make the plausible assumption that whether or not you will grow a new arm makes no difference to which material objects currently exist, then it follows that the object in question exists right now, quietly along for the ride as you finish up reading this paragraph. While I will not offer an argument against such a view, I'm willing to bet that many readers would prefer an alternative. ${ }^{2}$

\footnotetext{
${ }^{1}$ Chrysippus (c. 280 - c. 206 B.C.E.) was the original source of this puzzle, as reported by Philo of Alexandria in his On the Indestructibility of the World 48 (SVF 2.397). See Long and Sedley (1987, pp. 171172).

${ }^{2}$ As is well known, embracing counterpart theory or some similar treatment of de re modal predicates allows you to say that you are identical to the relevant object despite apparent modal differences between you and it. This move does little to enhance the appeal of the overall view.
} 
Each of these five implausible views has been held by one philosopher or another. ${ }^{3} \mathrm{My}$ own view, by contrast, has, to date, no representatives in the literature:

Dion has a foot but no foot-complement. Theon does not and never did exist, but Dion's ordinary parts—-his head, his feet, and so on-do exist. ${ }^{4}$

There are at least three arguments against this (dare I say) commonsense view. ${ }^{5}$ In this paper, I will resist these arguments. I think that just showing how to effectively resist these arguments is enough to reveal this view as the most attractive one available. But I won't argue for that, and I won't further criticize the alternatives. Moreover, I will help myself to the commonsense assumption that there are ordinary composite objects which can gain and lose parts, and also to the commonsense assumption that two material objects cannot share all their material parts, and cannot be exactly co-located. My main goal is just to convince you that my view is defensible.

\section{The arbitrariness argument}

Peter van Inwagen (1981) and Eric Olson (1995) each argue in favor of the view, mentioned above, that neither Theon nor Dion's left foot ever existed. Here is a shortened version of van Inwagen's argument that will suit my purpose:

Dion still exists after the annihilation of his left foot. And, if Theon ever existed, then Theon also continues to exist after the annihilation of Dion's left foot. Thus, if Theon ever existed, then Theon and Dion end up in the same place, having all their material parts in common. But this is absurd. So Theon never existed. And, since Theon does not differ from Dion's left foot in any metaphysically significant way, it would be

\footnotetext{
${ }^{3}$ Chisholm $(1973,1975,1976)$ accepts the first view, at least on the assumption that, prior to t, 'Dion' designates a material object shaped like an intact man. Burke (1994, 2004) accepts the second view. Dorr (2005) accepts the third view. Van Inwagen (1981; 1990, p. 172ff.) and Olson (1995, 1997a) accept the fourth view. And a large number of people accept the fifth view, either about Dion and Theon or about similar cases_for example: Wiggins (1968), Hirsch (1982, p. 59), Thomson (1983), Johnston (1992), Sider (2001, §5.8), and Heller (1990, p. 19); cf. Baker (2007, pp. 194-195) and Thomasson (2007, §10.3).

${ }^{4}$ Markosian (1998, pp. 242-243) is sympathetic to this view, although he does not quite endorse it.

${ }^{5}$ Actually, there is also a fourth, which I won't discuss here: the debunking argument. The idea of this argument is that there is no explanatory connection between the parts of an organism and ordinary attitudes about what parts an organism has, so that we have no reason to trust our ordinary judgments about the matter. For further discussion and a persuasive critique of this sort of argument that is congenial to my view, see Korman (2014a, §4.2; 2014b; 2015, chapter VII).
} 
unacceptably arbitrary to deny that Theon existed while accepting the existence of Dion's left foot. So it follows that neither Theon nor Dion's left foot ever existed.

And here is a shortened version of Olson's argument that will suit my purpose:

If Theon exists, then there are two things in the vicinity of Dion, namely Dion and Theon, who share a single brain and share all their thoughts. But only one thing has those thoughts, namely Dion. So Theon never existed. And, since Theon does not differ from Dion's left foot in any metaphysically significant way, it would be unacceptably arbitrary to deny that Theon existed while accepting the existence of Dion's left foot. So it follows that neither Theon nor Dion's left foot ever existed. ${ }^{6}$

There is something initially puzzling about both of these arguments. For it seems that one might reasonably ask: if it is unacceptably arbitrary to eliminate foot-complements but not eliminate feet, then why isn't it similarly arbitrary to eliminate foot-complements but not eliminate whole organisms? Furthermore, if one were comfortable denying that there are such ordinary, familiar things as hands and feet, why wouldn't one take seriously the possibility that there are no organisms at all?

For van Inwagen, the answer is that the whole organism is metaphysically privileged in virtue of the fact that the activities of the particles which compose it constitute a life (see his 1990, §9). And Olson holds that the whole organism is metaphysically privileged in virtue of being a unique thinker (1995, p. 182; 2007, chapter 8; also cf. Merricks 2001, chapter 4). Both of them therefore hold that the whole organism is metaphysically privileged in some relevant way that distinguishes it both from Theon and from Dion's left foot. Theon and Dion's left foot, on the other hand, are metaphysically on a par: both are arbitrary undetached parts.

In light of this, rather than claiming that van Inwagen and Olson are drawing an illicit distinction between organisms and their proper parts, I believe that a stronger response is to reject the premise that the relevant parts are metaphysically on a par. Specifically, I will claim, it is not the case that Dion's left foot is metaphysically on a par with Theon. This is

\footnotetext{
${ }^{6}$ Both of these arguments appeal crucially to arbitrariness. Proponents of the fifth view mentioned above (co-locationism) often make a similar appeal to arbitrariness in support of the thesis of plenitude, according to which every filled region of spacetime contains a great multitude of co-located objects—one for every modal profile. The idea is that it would be arbitrary to accept some but not all of these objects. See Hawley (2001, pp. 6-7), Bennett (2004, §4) and Hawthorne (2006, pp. vii-viii, chapter 3) for discussion, and see Korman (2010; 2015, chapter VIII) for a powerful critique of arbitrariness arguments for this sort of view.
} 
initially easy, as the arguments themselves highlight metaphysical differences between Theon and Dion's left foot.

For example, consider Olson's argument again. If this argument were correct, then the existence of Theon would entail the possibility of distinct thinkers sharing a single brain, since both Dion and Theon would overlap at the brain despite being distinct from one another (as only Dion ever has two feet). On the other hand, the existence of Dion's left foot would not have this consequence, since the analogous argument would obviously be absurd: Dion would not share a brain with his left foot, since his left foot has no brain as a part. So, if Olson's argument is otherwise correct, then (once again, by the lights of this very argument) the existence of Theon does entail, and the existence of Dion's foot does not entail, something metaphysically interesting and controversial: the possibility of distinct thinkers that share a single brain. Once again, this is a metaphysically significant difference between Theon, on the one hand, and Dion's left foot, on the other. It is therefore not true, as Olson says, that 'there is nothing ontologically special about [feet]', and Olson seems to be mistaken when he suggests that 'saying that there are [feet] but no [foot]complements would be as arbitrary as saying that there are [feet] but no [hands]. Any reasonable ontology of material objects that gives us [feet] gives us [foot]-complements as well' (1995, p. 183, with examples here and below changed for uniformity).

Or consider van Inwagen's argument again. If this argument were correct, the existence of Theon would entail the possibility of distinct mereological coincidents, since Dion and Theon are distinct, and both would persist through the annihilation of Dion's left foot, and would thereupon come to be coincident with each other. By contrast, the existence of Dion's left foot would not have this consequence, since Dion would not persist through the annihilation of the matter that makes up all his parts other than his left foot. So it seems that, by the lights of van Inwagen's own argument, the existence of Theon does entail, and the existence of Dion's left foot does not entail, something metaphysically interesting and controversial: the possibility of distinct objects that share all their material parts at a given time. This constitutes a metaphysically significant difference between Theon, on the one hand, and Dion's left foot, on the other. It is therefore not, as van Inwagen says, 'wholly arbitrary to accept the existence of [Dion's left foot] and to deny the existence of [Theon]' (1981, p. 82).

It would initially seem, therefore, that there is good reason to reject the key premise of both arguments: the premise that there is no metaphysically significant difference between Theon and Dion's left foot. The arguments themselves uncover such a difference, as both arguments apply to Theon in a way that similar arguments do not apply to Dion's left foot. 
I think that this basic response is effective against Olson's version of the arbitrariness argument. ${ }^{7}$ However, van Inwagen can now respond to my objection as follows. Suppose that there were an object inhabiting the space shaped like 'Dion's left foot minus Dion's left big toe.' Call this object Toeless. If Toeless exists, Dion's left foot can easily be caused to coincide with it by amputating Dion's left big toe. Thus, since co-location is, as van Inwagen and I agree, to be avoided, we must also agree that Toeless and Dion's left foot cannot both exist. I accept the existence of Dion's left foot, so it follows that I must deny the existence of Toeless. But, whereas van Inwagen has explained why it is non-arbitrary to accept the existence of Dion while denying the existence of Theon (namely, Dion, but not Theon, is composed of some things the activities of which constitute a life), one cannot similarly explain why it is non-arbitrary to accept the existence of Dion's left foot while denying the existence of Toeless. For Dion's left foot is not composed of some things the activities of which constitute a life, or any similar event. Thus, van Inwagen might join me in accepting the existence of Dion and rejecting the existence of Theon and Toeless, while claiming that - pending some as yet undiscovered metaphysical difference between Dion's left foot and Toeless - it would be metaphysically arbitrary not to reject the existence of Dion's left foot as well.

My reply is as follows. Suppose that Toeless exists (and thus Dion's left foot does not exist). Toeless was chosen totally arbitrarily: I might just as well have chosen to focus on putative objects in any of a great multitude of other arbitrary sub-regions of the location of Dion's left foot. So, if Toeless exists, there really are arbitrary objects in every sub-region of the location of Dion's left foot, and indeed in every sub-region of the location of Dion himself. But then, if Toeless can gain or lose parts, it can come to be co-located with these other arbitrary objects. Van Inwagen and I are assuming this to be impossible. So, if Toeless exists, it cannot gain or lose parts. ${ }^{8}$

Meanwhile, no such result holds if Dion's foot exists (and thus Toeless does not exist). For suppose that Dion's foot exists, but that there is no such thing as Toeless. In such a case, Dion's left foot is not an 'arbitrary' part of Dion: not every sub-region of Dion's location contains an object, since nothing is located in the location that would be the

\footnotetext{
${ }^{7}$ Olson might respond by suggesting that at least one of Dion's ordinary parts—his head—does not differ from Theon in any metaphysically significant way, since Dion's head has a brain as a part. Thus, he could argue that my approach still leads to the absurd result that human beings have no heads. This is Burke's objection, which I address below.

${ }^{8}$ More exactly, Toeless cannot gain parts that are made up of wholly new matter, or lose parts by having them totally annihilated. It may be that two hydrogen atoms that are parts of Toeless cannot survive swapping their electrons. If so, then swapping their electrons would result in the loss of those atoms as parts, and their replacement by two new hydrogen atoms. I do not mean to suggest that Toeless could not gain or lose parts in this way. For more on this issue, see Zimmerman (1995, esp. pp. 79-82) and Barnett (2004).
} 
location of Toeless if it existed. Given this, should we say that Dion's left foot is incapable of gaining and losing parts? It's hard to see why we would say such a thing, since we have ordinary reasons for thinking that Dion's left foot can survive, say, the clipping of its toenails.

In short, van Inwagen and I agree that Toeless and Dion's left foot don't both exist. If Toeless exists, then it cannot gain or lose parts. But Dion's left foot can gain and lose parts if it exists. This constitutes a metaphysically significant difference between the two objects. ${ }^{9}$ It is thus non-arbitrary to deny the existence of Toeless, while embracing the existence of Dion's left foot.

One might here object that, while I have identified a metaphysically significant difference between Dion's left foot and Toeless, it is not a metaphysically significant difference of the required kind. For, one might claim, what we want is an explanation of why the objects which compose Dion's foot manage to compose something, while the objects which would compose Toeless (if it existed) do not compose anything. This, one might think, requires an account of the relevant difference between the relationships among the objects which compose Dion's foot, on the one hand, and the relationships among the objects which (supposedly) compose Toeless, on the other, such that the former objects compose something, while the latter objects do not compose anything. The differences I have identified are not differences in the relationships among the relevant (supposed) composers, so, according to this objection, they are not differences of the right sort.

This objection can be easily answered. Consider Dion and Theon again. As mentioned above, the objects which compose Dion do so in virtue of the fact that their activities constitute a life. The activities of the alleged Theon-composers arguably do not constitute a life. So, if the alleged Theon-composers composed anything, it would be for some different sort of reason. And this should be no surprise. If there are objects like Theon, and (as I am assuming) co-location is impossible, then, as argued above, they cannot gain and lose parts. Surely we should expect the ground of composition to differ in some metaphysically substantial way between objects which cannot gain or lose parts, on the one hand, and those which can gain and lose parts, on the other. ${ }^{10}$ Since Toeless (if it exists) cannot gain or lose parts, while Dion's left foot can gain and lose parts, we should therefore

\footnotetext{
${ }^{9} \mathrm{~A}$ possible objection is that, because it is uncontroversial that spatial regions cannot gain or lose parts, there is nothing metaphysically significant or controversial about the existence of things that cannot gain or lose parts. But, if this is right, it is still metaphysically significant to suggest that there can be composite material objects that cannot gain or lose parts, since spatial regions are not material objects. Or, at any rate, it is at least controversial whether they are material objects, which is all that the present argument requires.

${ }^{10}$ Cf. Saenz (2018), who argues that, if there were objects such as Theon, they would have to be grounded by the mere existence of their parts, and that in fact this is incoherent.
} 
expect this sort of metaphysically substantial difference in the grounds of their status as composites. Hence, there is a metaphysically significant difference between Toeless and Dion's left foot: their status as composite objects is differently grounded. According to van Inwagen's arbitrariness argument, there is no such difference. So it looks like his argument fails.

Now van Inwagen might respond by claiming that it is impossible to give an adequate account of the facts of composition concerning Dion's left foot. More generally, he might claim that it is impossible to give a principled answer to the special composition questionthe question 'When do some things compose something?'-which generates such things as hands and feet without generating such things as Theon. I admit that I have no such answer (though see Carmichael (2015) for a start on an answer). But the fact that we have not produced a completely adequate commonsense answer to the special composition question —or the restricted version of the question about feet—is an extremely weak reason to reject the existence of feet. This would be like claiming that we should not believe in chairs or knowledge because we have not succeeded in defining chairhood or knowledge. If this is what the arbitrariness argument comes to, then the argument should convince no one. ${ }^{11}$

\section{The puzzle comes to a head}

Burke (1994, 2004) shares my inclination to preserve the existence of ordinary undetached parts of Dion such as his feet and his head. But he ultimately does not go along with my view that we can solve the puzzle of Dion and Theon by denying the existence of Theon and other arbitrary, undetached, mereologically constant parts. Here's why:

...even if this line has merit, it can provide only temporary relief. The case can be redescribed so that 'Theon' names the head of Dion, and what is successfully amputated is all of Dion except his head. Now, there will be no denying that there was such a thing as Theon... (1994, p. 132)

In other words, Burke thinks that the impulse to save ordinary parts of Dion (e.g., his feet or his head) is not well served by my approach of denying the existence of Theon. The

\footnotetext{
${ }^{11}$ Additionally, it may well be true that there is no such informative general answer to the special composition question, as Markosian (1998) suggests. And, even if there is such an answer, the attempt to articulate and defend it would be well-motivated only after seeing that the arguments that I am addressing in this paper do not succeed. My aim here is simply to take the first step of responding to some of the arguments that have led people away from the commonsense position.
} 
reason is that, in order to apply my approach to an altered version of the puzzle- one in which Dion is decapitated rather than having his foot amputated-Burke thinks that one must deny that Dion has a head. For Burke thinks that, in such a case, Dion's head plays the role that Theon played in the original puzzle. And, since my approach is in effect to deny the existence of the object that plays the role of Theon, my approach must lead us to deny the existence of human heads. But this does not accord with the common sense motivation for my view. In short: Burke thinks that he can reinstate the puzzle within the framework of ordinary parts that I'm advocating.

Let's grant the (unsettling!) claim that Dion would survive decapitation, at least for a moment. Now consider a related case in which we have a realistic copper statue of Dion. Would this statue go from being man-shaped to being head-shaped if it were 'decapitated' by annihilating all the parts that do not overlap the statue-head? It seems not. While a statue can plausibly gain and lose small parts, it cannot remain in existence upon suddenly losing over ninety percent of its mass. Such a catastrophic loss spells the end of the statue, not its reshaping. Thus, in assuming that Dion would survive decapitation for at least a moment, we are assuming that Dion is not like a statue of a man in this regard. But, if Dion is not like a statue of a man in this regard, then what is Dion? Is he a material object at all?

Some will react by opting for some form of dualism. ${ }^{12}$ And some will opt for the view that Dion is identical to (some part of) his brain or nervous system. ${ }^{13}$ On either of these views, one would presumably deny that any material object goes from being man-shaped to being head-shaped in the present case of decapitation, and so both views avoid any objectionable co-location of distinct material objects. Both of these views therefore manage to avoid Burke's objection, and both are consistent with my overall approach to the DionTheon puzzle. However, I find these views implausible, and I suspect that most readers do as well, so I would like to work out another reply.

The reply I favor proceeds from the idea that certain material objects are event-based objects, similar to a tornado, a hurricane, a wave in the ocean, an avalanche, a forest fire, and so on. ${ }^{14}$ Such objects depend for their continued existence on the ongoing occurrence

\footnotetext{
${ }^{12}$ Plantinga (2007) argues for substance dualism by way of similar considerations involving the sequential but sufficiently quick replacement of all my material parts with duplicates. I find this approach to the present puzzle implausible on the grounds that it does not plausibly generalize to lower organisms, for which puzzles similar to the puzzle of Dion and Theon can be raised.

${ }^{13}$ Parfit (2012) endorses this view and ably defends it from several of the obvious objections. Hudson (1999; 2001, chapter 4) seems to be committed to this view as well. See also Olson (2002, 2015) for discussion.

${ }^{14}$ See Carmichael (2015) for more on these objects, including an account of the sort of event that gives rise to such an object. In each of these examples, the named object is plausibly distinct from the underlying event since the object seems to have a different modal profile than the underlying event. E.g., the very same
} 
of an underlying event. Plausibly, organisms such as Dion are like this, with each organism depending for its continued existence on the ongoing occurrence of its life. ${ }^{15}$

If Dion is an event-based object of this sort, then his parts include all the objects whose activities constitute the relevant underlying event. As a result, Dion would have parts after the decapitation that do not overlap his head. Specifically, on the present assumptions, Dion is a material object that is capable of consciousness, and Dion's consciousness would continue on for at least a moment. Given these assumptions, it is very plausible that Dion's continued consciousness requires that Dion's brain would continue to contain the blood cells and electrical current that is involved in its normal functioning. These items would continue to be parts of Dion, since they play a key role in the momentary continuation of his life. But they would not be parts of his head: Dion's head intuitively does not lose any parts when the electrical activity in his brain ceases, although plainly enough his life ends and, given that he depends on the ongoing occurrence of the relevant event, he himself ceases to exist at that time. As a result, Dion would not perfectly overlap his head, but would continue to have his head as a proper part, contrary to Burke's worry. If, on the other hand, all Dion's parts that did not overlap his head-including all the blood and electrical current that is required for his continued consciousness-were destroyed, it is plausible that his life would not continue, and that he would not continue to be conscious, at least if (as we are assuming) he is a material object. And, if Dion's consciousness were extinguished in this way, it is plausible that he would no longer exist, and so he would not become co-located with his head.

An objection to this view arises in connection with Dion's body. One might think that, on the present view, prior to the decapitation, Dion is located where his body is. I have been assuming from the outset, though, that distinct material objects cannot be co-located. It follows that Dion is his body prior to the decapitation. His body plausibly does not survive reduction to a head. So one might be tempted to conclude that Dion must not survive the decapitation either, contrary to the view that he is an event-based object.

One response to this is to deny that Dion is where his body is on the view in question. For it seems plausible that the 'moving parts' within Dion's body-his blood cells, the electrical signals in his nervous system, etc.-are not parts of Dion's body. And so, since

tornado, hurricane, wave, forest fire, avalanche, etc., would have existed if it had been supported by some drastically shorter or longer event, but a given event plausibly cannot have been drastically shorter or longer. Nevertheless, see Zimmerman (1995, pp. 91-92; 2005, pp. 507-508) and Nolan (2011) for an alternative view on which objects like this are just identical to associated events.

${ }^{15}$ For more on the relevant notion of a life, see van Inwagen (1990, §9). Cf. Madden (2016a, 2016b) for an alternative 'function-based' view of persistence that could be appealed to here. 
these things are parts of Dion, Dion and his body overlap, but are in slightly different places.

But suppose that this is mistaken for one reason or another. In that case, it might seem that I am forced into the unfortunate choice of either denying that Dion survives the decapitation for at least a moment or adopting one of the other views mentioned above: the view that Dion is immaterial or the view that Dion is really a part of his nervous system. None of these options strikes me as plausible. Fortunately, there is another option. Specifically, if Dion is initially where his body is, then I want to claim that 'Dion's body' is a phase sortal that applies to Dion when he is shaped (roughly) like an intact man. On this view, Dion's body is not essentially Dion's body, but rather, at decapitation, it becomes a material object that is not a human body. We may then assert that Dion's body was destroyed, or that it did not survive, so long as by this we mean only that Dion's body ceased to be a human body, and did not survive as a human body. ${ }^{16}$

Before moving on to the next section, I want to make a final point in favor of the foregoing view. Specifically, the view I've been urging promises a satisfying solution to the 'many-thinkers' problem that has forcefully been raised in several places by Olson (1997b, 2003). For, according to the present approach, there is no material object in the vicinity of Dion (other than Dion) that has the capacity to think. Dion's brain and head lack parts of Dion that are integral and essential to his ability to think. His body might also lack these parts and therefore fail to think; on the other hand, if Dion's body does have these parts, then I have claimed that Dion is identical to Dion's body, where 'Dion's body' is a phase sortal referring to Dion while he has the relevant shape. Finally, Theon simply does not exist on my view, and so is not a competing thinker. So there is just one thinker: the material, event-based object - the organism - that is Dion. The avoidance of the manythinkers problem is an important advantage that my view holds over the first, second, and fifth views that I mentioned at the outset of this paper: namely, all the solutions other than the nihilistic or quasi-nihilistic views that deny the existence of human feet.

One additional candidate thinker that I haven't mentioned yet is the so-called mass of matter that is supposed to be where Dion is. I now deal with this and other problems my view faces in connection with these putative objects.

${ }^{16}$ Cf. Price (1977). One might wonder what we should say about corpses on this view. For we would normally say that, in a typical case, Dion's body continues to exist in the form of a corpse after Dion dies. And yet I've just claimed that Dion himself ceases to exist at death. It seems to follow that, in a typical case, Dion is not his body. But I've claimed that, so long as Dion is man-shaped, he is his body. My answer to this problem is to embrace what Olson (2013) calls ‘corpse creationism': at death, Dion ceases to exist, and the matter that previously made him up begins to constitute a newly existing corpse. As Olson (2004, §IV) has in effect argued, this is the natural view to adopt if you hold that Dion is an event-based object of the sort I've described. 


\section{Trouble with masses}

I've been assuming throughout that two material objects cannot share all their material parts, and cannot be exactly co-located. At the outset, I suggested that this assumption is motivated by an appeal to common sense. But Dean Zimmerman (1995, 2005) argues that this assumption is not well-motivated by common sense, and that it is in fact false. His argument is as follows. First, he takes it to be obvious that there are such things as the gold in my ring or the water in my glass, or, more to the present point, the matter in my body, and these things are just the sorts of things he means to be referring to by 'masses of matter'. As he puts it: 'we can hardly doubt that there are such things as these ... we talk about them all the time, and surely much of what we say about them is true' (2005, p. 494). So he thinks it is obvious that there are masses of matter, including the matter in any given human body. And he thinks it is a 'truism' that these things are mereologically constant: destroy a tiny bit of the gold that made up my ring on Tuesday, and my ring is no longer made up of the same gold on Wednesday. Finally, since these masses are in this way mereologically constant, and given that my body is obviously not mereologically constant, it follows that human bodies are distinct from but co-located with masses of matter. So he thinks it is pretty obvious - and in this respect, I take it, a commitment of common sensethat there are mereologically constant masses of matter, including such masses that are colocated with human bodies. If this line of reasoning is correct, it undercuts the commonsense aversion to co-location that motivates my own view. Furthermore, by similar reasoning, Zimmerman can argue that there is a mass of matter that inhabits $\mathrm{R}$, the subregion of Dion's exact location which excludes the exact location of his left foot: an object which would plausibly play the role of Theon in the puzzle of Dion and Theon. In this way, he can argue that Theon exists after all, contrary to my view. So, if Zimmerman's argument were successful, then not only would the commonsense motivation of my view be undercut; the view itself would be false.

One reply is to accept that there are masses of matter, but deny that masses of matter are single things. The idea is that 'the gold in my ring', while syntactically singular, is semantically plural, and refers plurally to the minimal pieces of gold that make up my ring. ${ }^{17}$ According to this theory, although the mass of gold that is co-located with my ring is not identical to my ring, it does not follow that there are distinct objects that are composed of the same gold atoms: the mass of gold is not an object, but some objects, and it is not even clear that it is composed of the gold atoms, or, at least, it isn't clear that there is any one sense of 'compose' such that the gold atoms compose both the mass and the

\footnotetext{
${ }^{17}$ Cf. Simons (2000, pp. 142-143) and Korman (2015, pp. 140-152).
} 
ring. On this view, Theon is just a mass of matter, and so the relationship between Theon and Dion after the loss of Dion's foot is the unexceptional relationship of composition: the relevant pieces of matter, which simply are Theon on this view, compose Dion at that time. Construed this way, Zimmerman's view is no longer inconsistent with my view.

Zimmerman (1995, §10) anticipates this response, and suggests that it fails when we attempt to apply it to pieces of atomless gunk: infinitely divisible matter all of whose proper parts themselves have proper parts. ${ }^{18}$ The problem is this. When we speak of a mass of gold, we may construe 'the mass of gold' as referring to the minimal pieces of gold (the gold atoms). But, when dealing with gunk, there are no minimal pieces. We could say that 'the mass of gunk' refers to all the bits of gunk, or we could arbitrarily choose pieces of gunk of some particular (perhaps microscopic) size to be the referents of the plural expression. ${ }^{19}$ But there is a significant problem with these approaches. For we can imagine the gunk in one of those pieces coming to form an organism-perhaps a very small onedistinct from the original piece. In such a case, given that we wish to avoid the co-location of organisms with masses of matter, we would be forced to say that one of the pieces of gunk was destroyed and replaced with an organism. But while one of the pieces of gunk was destroyed, the same gunk would intuitively be present before and after the destruction of that piece. Thus, 'the gunk' does not plurally refer to the relevant pieces of gunk.

In response, where ' $K$ ' stands for any concrete mass term (gold, gunk, etc.), I want to suggest a somewhat more complex treatment of expressions such as 'the $\mathrm{K}$ in the bottle'. In particular, I want to suggest a way of paraphrasing away all talk of masses. I will not try to get to the bottom of the exact relationship between the paraphrase and that which is paraphrased: perhaps the paraphrases are what the paraphrased claims meant all along, or perhaps the paraphrases provide 'what we really had in mind' while regarding the paraphrased claim as false. Or perhaps some other relationship holds. I assume only that the method of paraphrase is appropriate to the task of ontological reduction (or, if you prefer, elimination). ${ }^{20}$

\footnotetext{
${ }^{18}$ This definition probably needs to be refined in various ways that I am ignoring here. See Arntzenius and Hawthorne (2005, §2).

${ }^{19}$ Alternatively, we could claim that 'the mass of gunk' plurally refers to all the sub-masses of gunk, which are themselves pluralities of sub-sub-masses, which are, in turn, pluralities of further masses, and so on, as they say, 'all the way down.' See Zimmerman (1995, pp. 99-100) for a critique of this approach. I'm not sure Zimmerman's argument is right, but I won’t pursue the matter here.

${ }^{20}$ The paraphrase strategy I propose is similar to the semantics proposed in Nicolas (2008). One important difference is that, whereas Nicolas says (p. 232) that expressions like 'the gold in my ring' refer to all the pieces of gold that are parts of my ring, I do not say this. Nicolas's view seems to be that the gold in my ring today might be the same gold as the gold in my ring yesterday, even though 'the gold in my ring' refers to
} 
Consider first this claim:

The mass of gold in my ring is valuable.

I paraphrase thus:

There are some pieces of gold that compose my ring, and they are (jointly) valuable.

This sort of paraphrase handles most of what we want to say about masses. But, to deal with Zimmerman's objection, we need a treatment of claims like this:

The mass of matter in this bottle at $\mathrm{t}_{2}$ is the same as the mass that was in this bottle at $\mathrm{t}_{1}$.

For, in his example, the key judgment is that the same matter persists, and we need a paraphrase of such identity claims that does not require that all of the relevant pieces of matter persist. Here is my paraphrase:

There are some pieces of matter, the xs, such that:

(i) the $\mathrm{xs}$ are in this bottle at $\mathrm{t}_{1}$,

(ii) the $\mathrm{xs}$ are in the bottle at $\mathrm{t}_{2}$, and

(iii) none of the xs has different parts at $\mathrm{t}_{1}$ than at $\mathrm{t}_{2}$,

(iv) at both $t_{1}$ and $t_{2}$, each piece of matter in the bottle shares a part with one of the $x s$.

This approach deals nicely with Zimmerman's gunky organism example: it allows us to make the judgment that the same gunk is present before and after the organism forms even though different pieces of matter are present later than earlier, so long as there are some pieces in the bottle, the xs, such that, at each time, each piece in the bottle shares a part with one of the xs.

The general idea here is to appeal to the relationship of complete overlap that holds between things which jointly compose a whole, on the one hand, and the other parts of that whole, on the other. The composers of a thing completely overlap all of that thing's parts, but complete overlap can also hold between distinct pluralities of things where neither plurality composes anything, as when the molecules in a chamber completely overlap all the atoms in that chamber. This is the fact that allows the paraphrase to work without any commitment to a composite that is made up of the members of the plurality.

different things on each day. This seems to me mistaken. Cf. also Zimmerman's suggested 'more complex analysis' in his (2005, §3.7). 
Zimmerman anticipates a response similar to this, and he suggests that there's nevertheless something still implausible about this approach. Specifically, he thinks that it is implausible to claim, as the present view does, that if the parts of a given piece of gunk begin to compose an organism, then that piece of gunk ceases to exist. As he puts it: 'supposing that a mere hunk of matter should go out of existence owing to rearrangement of parts is ... a bit troubling' (2005, p. 514).

My reply is as follows. Zimmerman is suggesting that it is impossible for a hunk of matter to go out of existence owing to mere rearrangement of its parts. But Zimmerman and I agree that any given hunk of gunk could have its parts rearranged so as to compose a living organism. And, given this, the possibility that Zimmerman rejects follows directly from three very plausible premises:

(P1) Possibly, there is a kind of gunk $M$ such that, if some things compose a hunk of $M$, then they are securely bonded together-secure in the sense that they do not freely move with respect to each other.

(P2) If some things compose a living organism, then their activities constitute a life.

(P3) If the activities of some things constitute a life, then they are not securely bonded to one another.

Suppose that at $t_{1}$ we have a hunk of $M$. Then, given Zimmerman's view about rearrangement, the parts of $\mathrm{M}$ could be rearranged so as to form an organism at $\mathrm{t}_{2}$. If this does not destroy the hunk, then an organism is co-located with a composite piece of matter at $t_{2}$, and there are some things, the xs, which compose both the piece and the organism at that time. In that case, by (P1), the xs are securely bonded. And, by (P2), their activities constitute a life. But then, by (P3), a contradiction follows. Thus, it follows that no organism is co-located in this way with a composite piece of matter. And, given that (P1)(P3) are quite plausible, I deny that the view in question is really implausible, at least on reflection. $^{21}$

\section{Conclusion}

I have discussed three challenges to the commonsense view that Dion has hands and feet but no foot-complements: the objection that my view draws an arbitrary distinction

\footnotetext{
${ }^{21}$ Zimmerman objects that the approach I favor is inconsistent with the existence of blob-like organisms whose parts are continuous with each other. I disagree. The approach I favor is only inconsistent with 'hunk' organisms whose parts are securely bonded to each other.
} 
between Dion's ordinary parts and things like Theon, the objection that my view does not really solve the puzzle, which can be reinstated as focused on Dion's head, and the objection that my view does not handle the problem of masses. In each case, I have argued that the proponent of common sense has resources that have gone unnoticed, and which allow for an effective reply. If we can believe that there are such things as hands and feet without ending up involved in paradox, and without accepting large numbers of co-located material objects that share all their material parts, then that is what we should do. My view is the only known alternative which allows this. This provides a strong reason to accept the view I have been urging here. ${ }^{22}$

\section{References}

Arntzenius, Frank and John Hawthorne 2005: 'Gunk and Continuous Variation'. The Monist, 88(4), pp. 441-465.

Baker, Lynne Rudder 2007: The Metaphysics of Everyday Life. Cambridge: Cambridge University Press.

Barnett, David 2004: 'Some Stuffs are not Sums of Stuff'. Philosophical Review, 113(1), pp. 89-100.

Bennett, Karen 2004: 'Spatiotemporal Coincidence and the Grounding Problem'. Philosophical Studies, 118(3), pp. 339-371.

Burke, Michael 1994: 'Dion and Theon: An Essentialist Solution to an Ancient Puzzle'. The Journal of Philosophy, 91(3), pp. 129-139.

2004: 'Dion, Theon, and the Many-Thinkers Problem'. Analysis, 64(3), pp. 242250.

Carmichael, Chad 2015: 'Toward a Commonsense Answer to the Special Composition Question’. Australasian Journal of Philosophy, 93(3), pp. 475-490.

Chisholm, Roderick 1973: 'Parts as Essential to Their Wholes'. Review of Metaphysics, 26(4), pp. 581-603.

1975: 'Mereological Essentialism: Further Considerations'. Review of Metaphysics, 28(3), pp. 477-484. 1976: Person and Object: A Metaphysical Study. La Salle, IL: Open Court.

\footnotetext{
${ }^{22}$ Thanks to Merton College, Oxford for a generous Visiting Research Fellowship supporting this work. Ancestors of this paper were presented at Merton College and The Ohio State University; many thanks to the audiences on those occasions for helpful discussion. Special thanks to Ralf Bader, Michael Burke, Jason Eberl, Dan Korman, two anonymous referees, and the editors for Mind.
} 
Dorr, Cian 2005: 'What We Disagree About When We Disagree About Ontology’. In Mark Kalderon (ed.), Fictionalism in Metaphysics, pp. 234-286. Oxford: Clarendon Press. Hawley, Katherine 2001: How Things Persist. Oxford: Clarendon Press. Hawthorne, John 2006: Metaphysical Essays. Oxford: Oxford University Press. Heller, Mark 1990: The Ontology of Physical Objects: Four-Dimensional Hunks of Matter. Cambridge: Cambridge University Press.

Hirsch, Eli 1982: The Concept of Identity. New York: Oxford University Press.

Hudson, Hud 1999: ‘Temporal Parts and Moral Personhood’. Philosophical Studies, 93(3), pp. 299-316.

2001: A Materialist Metaphysics of the Human Person. Ithaca, NY: Cornell University Press.

Johnston, Mark 1992: 'Constitution is not Identity’. Mind, 101(401), pp. 89-104.

Korman, Daniel 2010: 'Strange Kinds, Familiar Kinds, and the Charge of Arbitrariness'. Oxford Studies in Metaphysics, 5, pp. 119-144.

2014a: 'Ordinary Objects'. In Edward Zalta (ed.), The Stanford Encyclopedia of Philosophy.

2014b: 'Debunking Perceptual Beliefs about Ordinary Objects'. Philosophers' Imprint, 14(13), pp. 1-21.

2015: Objects: Nothing out of the Ordinary. Oxford: Oxford University Press.

Long, A. A. and D. N. Sedley 1987: The Hellenistic Philosophers, Volume 1. Cambridge: Cambridge University Press.

Madden, Rory 2016a: 'Human Persistence’. Philosophers’ Imprint, 16(17), pp. 1-18.

2016b: 'Thinking Parts'. In Stephan Blatti and Paul F. Snowden (eds.), Animalism: New Essays on Persons, Animals, and Identity, pp. 180-207. Oxford: Oxford University Press.

Markosian, Ned 1998: 'Brutal Composition’. Philosophical Studies, 92(3), pp. 211-249

Merricks, Trenton 2001: Objects and Persons. Oxford: Clarendon Press.

Nicolas, David 2008: 'Mass Nouns and Plural Logic'. Linguistics and Philosophy, 31(2), pp. 211-244.

Nolan, Daniel 2011: 'Categories and Ontological Dependence’. The Monist, 94(2), pp. 277-300.

Olson, Eric 1995: 'Why I Have no Hands’. Theoria, 61(2), pp. 182-197.

1997a: 'Dion’s Foot'. Journal of Philosophy, 94(5), pp. 260-265.

1997b: The Human Animal: Personal Identity Without Psychology. Oxford: Oxford University Press.

2002: 'Review of Hud Hudson, A Materialist Metaphysics of the Human Person'. Notre Dame Philosophical Reviews. 
2003: ‘An Argument for Animalism’. In Raymond Martin and John Barresi (eds.), Personal Identity, pp. 318-334. Oxford: Blackwell.

2004: 'Animalism and the Corpse Problem'. Australasian Journal of Philosophy, 82(2), pp. 265-274.

2007: What Are We: A Study in Personal Ontology. Oxford: Oxford University Press.

2013: 'The Person and the Corpse'. In Fred Feldman and Jens Johansson (eds.), The Oxford Handbook of Philosophy of Death, pp. 80-96. Oxford: Oxford University Press.

2015: ‘On Parfit’s View that we are not Human Beings’. In Anthony O’Hear (ed.), Mind, Self, and Person, pp. 39-56. Ithaca, NY: Cornell University Press.

Parfit, Derek 2012: 'We are not Human Beings’. Philosophy, 87(1), pp. 5-28.

Plantinga, Alvin 2007: 'Materialism and Christian Belief'. In Dean Zimmerman and Peter van Inwagen (eds.), Persons: Human and Divine, pp. 99-141. Oxford: Oxford University Press.

Price, Marjorie 1977: ‘Identity Through Time’. Journal of Philosophy, 74(4), pp. 201-217.

Saenz, Noël. 2018. 'Sums and Grounding'. Australasian Journal of Philosophy, 96(1), pp. 102-117.

Sider, Theodore 2001: Four-Dimensionalism. Oxford: Oxford University Press.

Thomasson, Amie 2007: Ordinary Objects. Oxford: Oxford University Press.

Thomson, Judith Jarvis 1983: 'Parthood and Identity Across Time'. Journal of Philosophy 80(4), pp. 201-220.

Van Inwagen, Peter 1981: 'The Doctrine of Arbitrary Undetached Parts'. Pacific Philosophical Quarterly, 62, pp. 123-37. Page references in the text to the reprint in van Inwagen (2001).

1990: Material Beings. Ithaca, NY: Cornell University Press.

2001: Ontology, Identity, and Modality. Cambridge: Cambridge University Press.

Wiggins, David 1968: 'On Being in the Same Place at the Same Time'. The Philosophical Review, 77(1), pp. 90-95.

Zimmerman, Dean 1995: 'Theories of Masses and Problems of Constitution'. The Philosophical Review, 104(1), pp. 53-110.

2005: 'Material People'. In Michael Loux and Dean Zimmerman (eds.), The Oxford Handbook in Metaphysics, pp. 491-526. Oxford: Oxford University Press. 